Discussion Paper No. 810

\title{
ACCESS CHARGES, VERTICAL SEPARATION, AND LOBBYING
}

Toshihiro Matsumura

Noriaki Matsushima

May 2011

The Institute of Social and Economic Research

Osaka University

6-1 Mihogaoka, Ibaraki, Osaka 567-0047, Japan 


\title{
Access charges, vertical separation, and lobbying*
}

\author{
Toshihiro Matsumura ${ }^{\dagger}$ \\ Institute of Social Science, University of Tokyo \\ and \\ Noriaki Matsushima ${ }^{\ddagger}$ \\ Institute of Social and Economic Research, Osaka University
}

May 2, 2011

\begin{abstract}
We examine how vertical separation affects the lobbying activities for the access charge of essential facilities. First, when investigating a model where the number of new entrants is fixed, we find that vertical separation either increases or decreases the access charge, and that this depends on the relative efficiency between the incumbent and the new entrants, and the number of entrants. Second, when investigating a freeentry market, we find that vertical separation always reduces the access charge in such a market. The vertically integrated firm has a stronger incentive to lobby in this market because a higher access charge reduces the number of competitors.
\end{abstract}

JEL classification numbers: L51, L13

Key words: network industry, access charge, manipulation of accounting, regulation

\footnotetext{
${ }^{*}$ We would like to thank seminar participants at Osaka University and Kyoto University for their helpful comments. The authors gratefully acknowledge financial support from a Grant-in-Aid for Encouragement of Young Scientists and for Basic Research from the Japanese Ministry of Education, Science and Culture. Needless to say, we are responsible for any remaining errors.

${ }^{\dagger}$ Toshihiro Matsumura, Institute of Social Science, University of Tokyo, Hongo 7-3-1, Bunkyo, Tokyo 113-0033, Japan. E-mail: matsumur@iss.u-tokyo.ac.jp

${ }^{\ddagger}$ Corresponding author: Noriaki Matsushima, Institute of Social and Economic Research, Osaka University, Mihogaoka 6-1, Ibaraki, Osaka 567-0047, Japan. Phone: +81-6-6879-8571. E-mail: nmatsush@iser.osaka-u.ac.jp
} 


\section{Introduction}

Competition between a firm holding essential facilities (usually, a dominant firm) and firms not holding them has been widely observed in many industries such as overnight delivery, telecommunications, electric power, and natural gas distribution. In particular, in Japan, dominant firms are not vertically separated in telecommunications, electric power, and gas distribution. Dominant firms were previously legal monopolists, and they have had to compete against new entrants after the liberalization of these markets. New entrants pay an access fee to the dominant firms. The access charge (the price of using essential facilities that is also an input price for new entrants) affects the new entrants' marginal costs, and thus significantly affects the performance of the markets.

The access charge is typically regulated by the government. Considerable literature on the desirable and/or existing rules for levying the access charge, such as efficient component pricing rule (ECPR), total element long-run incremental cost (TELRIC), and a historical cost approach, exist; ${ }^{1}$ moreover, currently, charges based on the costs of essential facilities are levied all over the world. For example, in Japan, TELRIC has been adopted in traditional local telecommunications, while the historical cost approach has been adopted in optical fiber networks, electric power, and natural gas distribution. In the EU, although the rules are different for different countries, cost-based approaches have been adopted in most industries and in most countries.

In practice, however, firms often influence the access charge by lobbying and/or manipulating the accounting costs, whereas in principle, the rule for calculating the access charge is determined by a neutral government, and there is no room for manipulation. ${ }^{2}$ For example,

\footnotetext{
${ }^{1}$ For the general aspects of the access charge, see Vogelsang (2003) and Rey and Tirole (2007). See also Laffont and Tirole (1994), Economides and White (1995), Hausman (1997), Armstrong and Vickers (1998), Ida (2001), Sappington (2006), and Higgins and Mukherjee (2010). Further, see Hori and Mizuno (2006), Mizuno and Shinkai (2006), Ida and Anbashi (2008), and Gautier and Mitra (2008) for the dynamic efficiency of access charge rules.

${ }^{2}$ For discussions on these activities in the general context of regulation policies, see Viscusi et al. (2005).
} 
in Japan, integrated gas companies insisted that the costs of vaporizers and pumps of liquidated natural gas (LNG) tanks should be included in the access charge accounting for gas distribution pipeline networks. They made substantial efforts to rationalize their argument in front of the Gas Energy Committee of the Advisory Committee for Natural Resource and Energy, which is the agency that determines the rules for access charge accounting. Eventually, they succeeded in persuading the committee to adopt a resolution to include these costs in the current access charge. Similar instances have been widely observed in telecommunications and electric power distribution in Japan. In this paper, we consider a situation wherein the access charge is influenced by the firms through lobbying activities.

Another important topic in policy is whether dominant firms should be allowed to hold essential facilities. Vertical separation is always an important policy issue in this field, and ownership unbundling has been widely observed, especially in the EU. It is often insisted that vertical separation is beneficial because it deters manipulation by vertically integrated firms.

In this paper, we discuss the manner in which vertical separation affects the access charge. First, we formulate a model where $n$ firms compete in a final product market and one monopoly input supplier, firm 0, holds an essential facility. We compare two situations, firms 0 and 1 are vertically integrated (vertical integration case), and no firm is vertically integrated (vertical separation case).

We find that the effect of vertical separation on lobbying activities are ambiguous. It depends on the number of firms and the cost structure. When the number of firms is large, vertical separation decreases (increases) the lobbying activities and consequently the access charge if the incumbent is more efficient than or as efficient as the new entrants (if the incumbent is considerably less efficient than the new entrants). On the contrary, when the number of firms is small, vertical separation increases (decrease) the access charge if the incumbent is more efficient than or as efficient as the new entrants (if the incumbent is considerably less efficient than the new entrants). We also discuss the welfare effects. We 
find that vertical separation can be harmful for welfare.

Second, we investigate a free-entry market of new entrants. ${ }^{3}$ We obtain a contrasting clear-cut result. We find that vertical separation reduces the access charge in the free-entry market. The vertically integrated firm has a stronger incentive to increase the access charge in a free-entry market because a higher access charge reduces the number of competitors. Such a strategic effect disappears under vertical separation.

We now review related papers. The aim of this paper is to investigate the relationship between the incentive to raise the access charge and vertical separation/integration. ${ }^{4}$ In the literature on vertically related industries, many works have already pointed out that vertically integrated firms have strong incentives to raise their rivals' costs. Economides (1998) investigates Cournot competition in a downstream market and shows that the vertically integrated firm has an incentive to exclude the rivals through a prohibitive access charge. Mandy and Sappington (2007) show that the vertically integrated firm has an incentive to engage in cost-increasing sabotage regardless of whether there is Cournot or Bertrand competition in the downstream market, but has a weak (strong) incentive to engage in demand-reducing sabotage when there is Bertrand (Cournot) competition. The discussions on increasing the rivals' costs and cost-increasing sabotage in this context are also provided by Beard et al. (2001) (see also the papers cited by them). Bustos and Galetovic (2009) discuss a case in which a bottleneck monopoly endogenously determines its vertical structure (integration or separation) and the degree of sabotage.

The setting of lobbing activity in this paper is closely related to the cost-increasing sabotage discussed in the previous researches, but there is one crucial difference. Under vertical separation, the upstream firm has no incentive to engage in sabotage activities because these activities never increase the revenue of the upstream firm (Beard et al. (2001) and Mandy and Sappington (2007)). Thus, vertical separation never facilitates sabotage

\footnotetext{
${ }^{3}$ Free entry markets often yield completely different economic implications (Lahiri and Ono (1995), Davidson and Mukherjee (2007), Etro (2007), Marjit and Mukherjee (2008), and Ino and Matsumura (2010)).

${ }^{4}$ Armstrong and Sappington (2006) provide a comprehensive survey for deregulation policy.
} 
activities. On the contrary, the vertically separated upstream firm still has an incentive to lobby because an increase in the access charge can increase its profits. As a result, vertical separation can facilitate lobbying activities. Another difference is that all works mentioned above assume that the number of firms is given exogenously, while we consider a free-entry market. ${ }^{5}$

The remainder of this paper is organized as follows. Section 2 formulates the model and provides the basic calculus to derive the main result. Section 3 presents the main results. Section 4 discusses a free-entry market. Section 5 concludes the paper.

\section{The Model}

We consider two cases: (1) a vertically integrated firm holding an essential facility and (2) vertical separation undertaken by the government. We call the firm holding an essential facility the integrated (separated) facility firm in the integration (separation) case, respectively.

\subsection{Vertical integration case}

We consider an oligopoly model. Firm 1 is an integrated facility firm, and firm $i$ ( $i=$ $2, \ldots, n)$ is a new entrant. Firm $i$ accesses the essential facility held by firm 1 and pays $a y_{i}$ to firm 1 , where $a$ is the per unit access charge and $y_{i}$ is firm $i$ 's output. ${ }^{6}$

In the first stage, the access charge (input price) $a$ is determined. Let $L(a)$ denote firm 1's effort costs (costs incurred for the lobbying activity, manipulation of the access charge

\footnotetext{
${ }^{5}$ The model formulation is also related to that in Buehler et al. (2006). They consider the effects of policy instruments to a public utility which supplies an essential input to downstream firms and engages in quality investment: (i) market structure regulation (vertical separation/integration with downstream competition and monopoly vertical integration) and (ii) access charge regulation. They mainly focus on how vertical separation/integration with downstream competition and the level of access charge change the price in the downstream market and the service quality. This is different from the main concern in our paper.

${ }^{6}$ In many countries, the sales and production departments of a vertically integrated firm pay ay to their own network department that holds the essential facilities. However, this accounting system does not affect the optimal output in an integrated firm as long as it maximizes the joint profit of both departments.
} 
accounting, etc.). We implicitly assume that the per unit access charge is zero if firm 1 does not make any effort. That is, the access charge is regulated but can be affected by firm 1's efforts. Moreover, we only consider the cases in which only the integrated/separated facility firm engages in lobbying activities. This is because we would like to clarify how vertical integration/separation affects firm 1's incentive to lobby. In the discussion on lobbying activities, this simple functional form is often employed. For instance, Long and Soubeyran (1996), Pecorino (1998), and Yamazaki (2004) among others assume that in the context of international trade, the tariff rate $t$ is a function of the domestic firms' total lobbying efforts/expenditures or the industry-wide labor devoted to lobbying, and that the tariff function $t=t(Z)$ satisfies $t^{\prime}>0$ and $t^{\prime \prime}<0$, where $Z=\sum_{i=1}^{n} z_{i}$, and $z_{i}$ is the effective lobbying effort/expenditure of the domestic firm $i$. We think that this simple assumption clarifies how the main results in this paper are derived. ${ }^{7}$

In the second stage, the firms engage in Cournot competition. They simultaneously produce perfectly homogeneous products for which the market demand function is given by $p(Y)=v-Y$, where $v$ is a positive constant and $Y$ is the total output of the firms (price as a function of quantity). Firm $i$ 's production cost (except for the access charge) is normalized to zero and firm 1's marginal production cost is denoted by $c$. If $c$ is positive (negative), firm 1 is less (more) efficient than firm $i(i=2, \ldots, n)$. Firm 1's profit and firm $i$ 's profit are given as $(i=2, \ldots, n)$

$$
\pi_{1}=(p(Y)-c) y_{1}+a \sum_{j=2}^{n} y_{j}-L(a), \quad \pi_{i}=(p(Y)-a) y_{i} .
$$

We assume that $L^{\prime}(a) \geq 0$ and that $L^{\prime \prime}(a)>0$ in order to ensure the concavity of

\footnotetext{
${ }^{7}$ It might be possible to formulate these lobbying activities by other models. For instance, lobbying activities are often formulated by the rent-seeking model of Tullock (1980), which is also related to patent race games (e.g., Loury (1979), Dasgupta and Stiglitz (1980), and Clark et al. (2010)). In these models, it is often assumed that each player engages in lobbying activities and that the winner of the rent-seeking game (patent race game) is probabilistically determined. As the effort (investment) level of a player increases, his/her winning probability increases. This property is somewhat similar to that formulated in this paper although the access charge is deterministically set by the effort level of the integrated/separated facility firm.
} 
firm 1's payoff function. We assume that $L^{\prime}(0)=0$ in order to ensure interior solutions in the first stage. We also assume interior solutions in the second stage (production stage) discussed below.

Consider the second stage. The reaction functions of the firms in the second stage are given by

$$
R_{1}\left(Y_{-1}\right)=\frac{v-c-\sum_{j=2}^{n} y_{j}}{2}, \quad R_{i}\left(Y_{-i}\right)=\frac{v-a-\sum_{j \neq i} y_{j}}{2} .
$$

The resulting equilibrium outputs and profits are as follows $(i=2,3, \ldots, n)$ :

$$
\begin{aligned}
& y_{1}^{I S}=\frac{v-n c+(n-1) a}{n+1}, \quad y_{i}^{I S}=\frac{v+c-2 a}{n+1}, \quad Y^{I S} \equiv \sum_{j=1}^{n} y_{j}^{I S}=\frac{n v-c-(n-1) a}{n+1}, \\
& \pi_{1}^{I S}=\frac{(v-n c+(n-1) a)^{2}}{(n+1)^{2}}+\frac{a(n-1)(v+c-2 a)}{n+1}-L(a), \quad \pi_{i}^{I S}=\frac{(v-2 a+c)^{2}}{(n+1)^{2}} .
\end{aligned}
$$

where the superscript $I S$ denotes the equilibrium outcome under vertical integration in the second stage. The resulting total social surplus (consumer surplus plus the profits of the firms) is given $b y^{8}$

$$
W^{I S}=\frac{(n v-c-(n-1) a)((n+2) v+c+(n-1) a)}{2(n+1)^{2}}-\frac{c(v-n c+(n-1) a)}{n+1}-L(a) .
$$

In the first stage, firm 1 maximizes $\pi_{1}^{I S}$ with respect to $a$. The first-order condition is

$$
\frac{\partial \pi_{1}^{I S}}{\partial a}=\frac{2(n-1)(v-n c+(n-1) a)}{(n+1)^{2}}+\frac{(n-1)(v+c-4 a)}{n+1}-L^{\prime}(a)=0 .
$$

Let the superscript $I$ denote the subgame perfect Nash equilibrium (SPNE) outcomes under vertical integration. $a^{I}$ is derived from (2).

\section{$2.2 \quad$ Vertical separation case}

We consider the situation wherein vertical separation is undertaken by the government. In the previous subsection, firm 1 holds the essential facility and supplies the final products. In this subsection, firms 0 and 1 are separated. Firm 0 holds the essential facility but does not supply the final products. It obtains access revenue from $n$ firms including firm 1 .

\footnotetext{
${ }^{8}$ If the lobbying costs are not real social costs but only income transfers from the firm to the regulators or lawyers, it might be better not to subtract $L(a)$ in (1).
} 
In the first stage, firm 0 chooses $a$ with cost $L(a)$. After observing $a, n$ firms compete in terms of output. Firm 0's profit, firm 1's profit, and firm $i$ 's profit are given by $(i=2, \ldots, n)$

$$
\pi_{0}=a \cdot \sum_{i=1}^{n} y_{i}-L(a), \quad \pi_{1}=(p(Y)-c-a) y_{1}, \quad \pi_{i}=(p(Y)-a) y_{i} .
$$

Again, in the second stage, $n$ firms engage in Cournot competition.

We discuss the second stage subgame where $a$ is given exogenously. The equilibrium outputs are as follows $(i=2,3, \ldots, n)$ :

$$
y_{1}^{S S}=\frac{v-n c-a}{n+1}, \quad y_{i}^{S S}=\frac{v+c-a}{n+1}, \quad Y^{S S}=\frac{n v-c-n a}{n+1},
$$

where the superscript $S S$ denotes the equilibrium outcome under vertical separation in the second stage. The resulting profits of the firms are given by $(i=2,3, \ldots, n)$

$$
\pi_{0}^{S S}=\frac{a(n v-c-n a)}{n+1}-L(a), \quad \pi_{1}^{S S}=\frac{(v-n c-a)^{2}}{(n+1)^{2}}, \quad \pi_{i}^{S S}=\frac{(v+c-a)^{2}}{(n+1)^{2}} .
$$

The resulting total social surplus is given by

$$
W^{S S}=\frac{(n v-c-n a)((n+2) v+c+n a)}{2(n+1)^{2}}-\frac{c(v-n c-a)}{n+1}-L(a) .
$$

In the first stage, firm 0 maximizes its profit with respect to $a$. The first-order condition is given by

$$
\frac{\partial \pi_{0}^{S S}}{\partial a}=\frac{n v-c-2 n a}{n+1}-L^{\prime}(a)=0
$$

Let the superscript $S$ denote the SPNE outcomes under vertical separation. $a^{S}$ is derived from (3).

\section{Results}

We now present the results.

Proposition 1 (i) If $n<3$, there exists $\tilde{c}(n)$ such that $a^{S}>a^{I}$ if and only if $c<\tilde{c}(n)$.

(ii) If $n=3, a^{S}=a^{I}$ regardless of $c$.

(iii) If $n>3$, there exists $\bar{c}(n)$ such that $a^{S}>a^{I}$ if and only if $c>\bar{c}(n)$. 
Proof: See Appendix.

The following figures are helpful for understanding Proposition 1. In the figures, $\bar{\pi}_{i}$ indicates the profit of firm $i$ before subtracting lobbying cost $L(a) . \partial \bar{\pi}_{1}^{I S} / \partial a$ and $\partial \bar{\pi}_{0}^{S S} / \partial a$ respectively denote the marginal gains of raising $a$ for the facility firms in the integration and the separation cases. $L^{\prime}(a)$ denotes the marginal cost of raising $a$ in both cases. Figures 1(a), 1(b), 1(c), and 1(d) indicate the cases in which $n$ is small and $c$ is large, both $n$ and $c$ are large, both $n$ and $c$ are small, and $n$ is large and $c$ is small, respectively. They show the equilibrium access charge levels in each case.

\section{[Figure 1 here]}

A key property behind Proposition 1 is that the slope of $\partial \bar{\pi} / \partial a$ depends on the number of firms. Figure 1 shows that $\left|\partial^{2} \bar{\pi}_{1}^{I S} / \partial a^{2}\right|>\left|\partial^{2} \bar{\pi}_{0}^{S S} / \partial a^{2}\right|\left(\operatorname{resp} .\left|\partial^{2} \bar{\pi}_{1}^{I S} / \partial a^{2}\right|<\left|\partial^{2} \bar{\pi}_{0}^{S S} / \partial a^{2}\right|\right)$ holds if $n$ is large (resp. small). We now discuss the intuition behind this property.

We rewrite the marginal gains of raising $a$ for the facility firms in the two cases (integration and separation cases) as follows:

$$
\begin{aligned}
& \frac{\partial \bar{\pi}_{1}^{I S}}{\partial a}=p^{\prime}(Y) \sum_{i=2}^{n} \frac{\partial y_{i}^{I S}(a)}{\partial a} y_{1}^{I S}(a)+\sum_{i=2}^{n}\left(y_{i}^{I S}(a)+a \frac{\partial y_{i}^{I S}(a)}{\partial a}\right) \\
& \frac{\partial \bar{\pi}_{0}^{S S}}{\partial a}=\sum_{i=1}^{n}\left(y_{i}^{S S}(a)+a \frac{\partial y_{i}^{S S}(a)}{\partial a}\right) .
\end{aligned}
$$

We call the first term in the first equation "the strategic effect." This represents the incentive of the integrated facility firm for reducing its rivals' outputs. We call the remaining effects in the two equations "the input-market effect." This represents the incentives of the facility firms in both cases for obtaining access charge revenues. Note that in the separation case, only the input-market effect exists.

We now investigate the condition that $\left|\partial^{2} \bar{\pi}_{1}^{I S} / \partial a^{2}\right|>\left|\partial^{2} \bar{\pi}_{0}^{S S} / \partial a^{2}\right|$. First, we discuss the input-market effect. In both integration and separation cases, a higher $a$ leads to a lower output of firms paying the access charge (we call them service-based firms) because it increases their marginal costs (direct effect). In the integration case, a higher $a$ leads 
to a higher output of firm 1, and it further reduces the total output of the service-based firms (indirect effect), while no such additional indirect effect exists in the separation case. This means that an increase in $a$ reduces the total output of service-based firms more in the integration case than in the separation case. Thus, an increase in $a$ weakens the input-market effect more in the integration case than in the separation case. Therefore, $\left|\partial^{2} \bar{\pi}_{1}^{I S} / \partial a^{2}\right|>\left|\partial^{2} \bar{\pi}_{0}^{S S} / \partial a^{2}\right|$ holds unless the input-market effect is dominated by the strategic effect, which is discussed below.

Next, we discuss the strategic effect. There is no strategic effect in the separation case. However, in the integration case, a higher $a$ leads to a higher $y_{1}^{I S}(a)$, which strengthens the strategic effect. In other words, an increase in $a$ enhances the marginal gain of raising $a$ from the strategic effect. Therefore, $\left|\partial^{2} \bar{\pi}_{1}^{I S} / \partial a^{2}\right|<\left|\partial^{2} \bar{\pi}_{0}^{S S} / \partial a^{2}\right|$ holds as long as the strategic effect dominates the input-market effect discussed above.

We now discuss how $n$ affects these two effects. An increase in $n$ increases the total output of service-based firms. Thus, it strengthens the input-market effect. The effect on the strategic effect is complicated. On the one hand, an increase in $n$ increases $\sum_{i \neq 1} \partial y_{i}^{I S}(a) / \partial a$ and strengthens the strategic effect. On the other hand, an increase in $n$ reduces $y_{1}^{I S}(a)$ and weakens the strategic effect. The above two effects are mutually canceled out, and the net effect is weak. Under these conditions, the input-market effect is more likely to dominate the strategic effect when $n$ is larger. Hence, $\left|\partial^{2} \bar{\pi}_{1}^{I S} / \partial a^{2}\right|>\left|\partial^{2} \bar{\pi}_{0}^{S S} / \partial a^{2}\right|$ holds unless $n$ is small enough.

Another key property behind Proposition 1 is that the intersection of the two curves of marginal gains in the two cases is $((v-n c) / 2,(n-1) c)$. The location of the intersection depends on the efficiency of firm $1, c$, and the number of firms, $n$. A decrease in $c$ shifts the two curves of marginal gains toward the northeast. The shift of $\partial \bar{\pi}_{1}^{S S} / \partial a$ is larger (resp. smaller) than that of $\partial \bar{\pi}_{0}^{I S} / \partial a$ when $n$ is small (resp. large). The shifts of the two curves induce the intersection to move toward the southeast (compare (a) with (c), and (b) with (d)). We explain the intuition behind the property of these shifts. 
First, we explain how a decrease in $c$ increases the marginal gains in both cases and yields the upward shifts of both curves, $\partial \bar{\pi}_{1}^{S S} / \partial a$ and $\partial \bar{\pi}_{0}^{I S} / \partial a$. A higher efficiency of the integrated facility firm (a lower $c$ ) leads to its higher quantity $y_{1}^{I S}(a)$. The strategic effect is strong when the quantity supplied by the integrated facility firm $\left(y_{1}^{I S}(a)\right)$ is large. Thus, a decrease in $c$ strengthens the strategic effect in the integration case, resulting in an upward shift of the curve, $\partial \bar{\pi}_{0}^{I S} / \partial a$. In the separation case, a lower $c$ leads to a higher total output of the service-based firms $\left(\sum_{i=1}^{n} y_{i}^{S S}(a)\right)$. A lower $c$ implies that the average of the firms' marginal costs is smaller. As Salant and Shaffer (1999) show, it yields a larger total output. Thus, a decrease in $c$ strengthens the input-market effect in the separation case, resulting in an upward shift of the curve, $\partial \bar{\pi}_{1}^{S S} / \partial a$.

Next, we explain how a decrease in $c$ yields a smaller shift of the curve in the separation case when $n$ is large. The impact of a decrease in $c$ on the average marginal cost is smaller when $n$ is large, and consequently, the marginal gain in the separation case is less sensitive to $c$. On the contrary, in the integration case, the impact of a decrease in $c$ on the strategic effect is stronger when $n$ is large. The impact of a decrease in $c$ on $y_{1}^{I S}$ is stronger when $n$ is larger. In fact, $\left|\partial y_{1}^{I S} / \partial c\right|=n /(n+1)$, and this is increasing in $n$. The rest of the parts consisting the strategic effect do not depend on $c .{ }^{9}$ As a result, the marginal gain in the integration case is more sensitive to $c$ when $n$ is large. Under these conditions, the upward shift of the curve, $\partial \bar{\pi}_{0}^{I S} / \partial a$, which is caused by a decrease of $c$ in the integration case, dominates that of $\partial \bar{\pi}_{1}^{S S} / \partial a$ in the separation case when $n$ is large, resulting in the right-down shift of the intersection (see Figures 1(b) and 1(d)).

We briefly discuss the welfare implications of vertical separation. Vertical separation yields a double-marginalization problem in firm 1 and reduces its output. Although it increases the other firms' outputs, the total output decreases by vertical separation. Given $a$, vertical separation reduces $y_{1}$ and $Y$, and hence reduces welfare. Suppose that $c \leq 0$.

\footnotetext{
${ }^{9}$ This property would depend on the assumption of the inverse demand function. We consider that the weak relation between the rest of the parts and $c$ holds, even though we use a more general inverse demand function.
} 
According to Proposition 1(i), vertical separation increases $a$ when $n=2$, which results in a welfare loss. Because both effects reduce welfare, vertical separation unambiguously reduces welfare. When $n=3$, the second effect disappears, but the first effect is still present. Thus, vertical separation unambiguously reduces welfare when $n=3$. These yield the following proposition:

Proposition 2 If $n \leq 3$, vertical separation reduces welfare when $c \leq 0$.

When $c$ is positive, however, the implications on welfare are ambiguous even when $n \leq 3$. When $c$ is large, a reduction in firm 1's output and an increase in the outputs of the other downstream firms improve welfare because the other firms are more efficient than firm 1 (total production costs are economized). This effect is known as the welfare-improving production substitution effect. ${ }^{10}$ Moreover, vertical separation decreases $a$ (Proposition 1(ii)), resulting in a welfare gain. Although these two effects improve welfare, vertical separation induces a decrease in the total output, which reduces welfare. Thus, whether the former welfare-improving effect dominates the latter welfare-reducing effect is ambiguous.

When $n>3$, the welfare implication of vertical separation becomes further complicated. Suppose that $c \leq 0$. Given $a$, vertical separation reduces firm 1's output and increases the other firms' outputs. However, because it reduces the total output, it reduces welfare as in the case where $n \leq 3$. According to Proposition 1(iv), if $c \leq 0$, vertical separation decreases $a$ when $n>3$, which results in a welfare gain. Thus, whether the latter welfare-improving effect dominates the former welfare-reducing effect is ambiguous.

We now specify $L(a)=\phi a^{2} / 2$ and present a numerical result where $\phi$ is a positive constant. Suppose that $c=0$. Figure 2 indicates the condition wherein vertical separation reduces welfare. This figure indicates that when $n$ or $\phi$ is large, vertical separation improves welfare.

\footnotetext{
${ }^{10}$ See Lahiri and Ono $(1988,1998,1999)$. Production substitution plays a crucial role in the discussions on public policies. See, among others, Ono (1990), Ushio (2000), Matsushima (2001), Matsumura (2003), Matsushima and Matsumura (2003), and Ishida et al. (2010).
} 
[Figure 2 here]

The larger the value of $n$, the weaker the double marginalization effect discussed above (the welfare-reducing effect of vertical separation). Thus, vertical separation is more likely to improve welfare when $n$ is larger. The larger the value of $\phi$, the larger the lobbying cost $L(a)=\phi a^{2} / 2$, given a fixed $a$. Although the absolute values of $a^{I}$ and $a^{S}$ decrease with $\phi$, the difference between $a^{I}$ and $a^{S}$ affects the welfare difference between the two cases (note that $a^{I}>a^{S}$ ). Thus, vertical separation is more likely to improve welfare when $\phi$ is large.

Remark In our model, vertical separation reduces welfare when $c \leq 0$ and $n \leq 3$ (Proposition 2). However, we should not excessively emphasize this result. We have assumed that the facility firms in the two cases have the same manipulation cost function $L(a)$. This assumption may not be realistic. Under vertical separation, the cost structure becomes more transparent and the disintegrated upstream firm faces more difficulties in manipulating the accounting costs. In such situations, the access charge is lower than that predicted by our model. Thus, our model might underestimate the gains from vertical separation.

\section{Free entry}

In the previous section, the number of firms in the product market is given exogenously. However, if we consider the entries of independent firms, the results may change. Under vertical separation, the separated facility firm has an incentive to reduce the access charge in order to stimulate new entries. On the contrary, the integrated facility firm has an opposite strategic incentive. It strategically increases the access charge in order to deter further entries. Thus, if we consider a possible further new entry, vertical separation might reduce the access charge even when the incumbent is as efficient as the new entrants. In this section, we examine this problem. ${ }^{11}$

\footnotetext{
${ }^{11}$ In this paper, we consider the situation in which $a$ is determined before entry. If $a$ is determined after entry, the basic principle discussed in the previous section can also apply to the free-entry market case. Thus, vertical separation can either increase or decrease the access charge, depending on the relative production
} 
We now consider a case in which new entrants freely enter the market after the value of $a$ is determined. The input price $a$ is common among the final product suppliers. Let $F$ be the entry cost of each new entrant. We assume that $c<\sqrt{F}$. Otherwise, the incumbent exits from the final product market in both the vertical integration case and the vertical separation case; thus, vertical separation never affects the equilibrium access charge. ${ }^{12}$

Vertical integration We consider the vertical integration case with free-entry. First, we consider the equilibrium in the second stage (quantity competition stage). The resulting equilibrium outputs and profits are the same as fixed $n$ case except that $(i=2,3, \ldots, n)$

$$
\pi_{i}^{I S}=\frac{(v-2 a+c)^{2}}{(n+1)^{2}}-F,
$$

where $F$ is the entry cost of each independent firm. From the free-entry condition (zeroprofit condition), we have the equilibrium number of firms:

$$
n=\frac{v+c-2 a-\sqrt{F}}{\sqrt{F}} .
$$

The resulting equilibrium outputs and profits are as follows $(i=2,3, \ldots, n)$ :

$$
\begin{aligned}
& y_{1}^{I S}=\sqrt{F}+(a-c), \quad y_{i}^{I S}=\sqrt{F}, \quad Y^{I S}=v-\sqrt{F}-a, \\
& \pi_{1}^{I S}=(\sqrt{F}-c)^{2}+(v-c) a-a^{2}-L(a), \quad \pi_{i}^{I S}=0, \\
& W^{I S}=\frac{(v-\sqrt{F}-a)^{2}}{2}+(\sqrt{F}-c)^{2}+(v-c) a-a^{2}-L(a) .
\end{aligned}
$$

Second, we consider the first stage. The integrated facility firm maximizes $\pi_{1}^{I S}$ with respect to $a$. The first-order condition is

$$
\frac{\partial \pi_{1}^{I S}}{\partial a}=v-c-2 a-L^{\prime}(a)=0 .
$$

Let the superscript $I$ denote the subgame perfect Nash equilibrium (SPNE) outcomes under vertical integration. $a^{I}$ is derived from (4).

efficiency between the incumbent and the new entrants, and the entry cost that affects the equilibrium number of entrants.

${ }^{12}$ Under vertical separation, we can see this from $y_{1}^{S S}$ in (5). Under vertical integration, we can show that exiting from the final product market before the entry of rival firms increases the profit of firm 1 if and only if $c \geq \sqrt{F}$. Thus, even here, firm 1 is not active in the final product market. 
Vertical separation We consider the vertical separation case with free-entry. Fist, we consider the equilibrium outcome in the second stage. The resulting equilibrium outputs and profits are the same as fixed $n$ case except for $(i=2,3, \ldots, n)$

$$
\pi_{i}^{S S}=\frac{(v+c-a)^{2}}{(n+1)^{2}}-F .
$$

From the free-entry condition, we have the equilibrium number of firms:

$$
n=\frac{v+c-a-\sqrt{F}}{\sqrt{F}} .
$$

The resulting equilibrium outputs and profits are as follows $(i=2,3, \ldots, n)$ :

$$
\begin{aligned}
& y_{1}^{S S}=\sqrt{F}-c, \quad y_{i}^{S S}=\sqrt{F}, \quad Y^{S S}=(v-a)-\sqrt{F}, \\
& \pi_{0}^{S S}=(v-\sqrt{F}-a) a-L(a), \quad \pi_{1}^{S S}=(\sqrt{F}-c)^{2}, \quad \pi_{i}^{S S}=0, \\
& W^{S S}=\frac{(v-\sqrt{F}-a)^{2}}{2}+(\sqrt{F}-c)^{2}+(v-\sqrt{F}) a-a^{2}-L(a) .
\end{aligned}
$$

In the first stage, firm 0 maximizes its profit with respect to $a$. The first-order condition is given by

$$
\frac{\partial \pi_{0}^{S S}}{\partial a}=v-\sqrt{F}-2 a-L^{\prime}(a)=0 .
$$

Let the superscript $S$ denote the SPNE outcomes under vertical separation. $a^{S}$ is derived from (6).

Because we assume that $c<\sqrt{F}$, from (4) and (6), we have the following proposition: ${ }^{13}$ Proposition $3 a^{S}<a^{I}$. That is, the input price decrease under vertical separation.

Under free-entry, an additional strategic effect emerges. Under vertical integration, a higher input price diminishes the incentive of the new entrants to enter the market. This higher price protects the integrated downstream incumbent. Thus, the integrated facility firm has a strong incentive to raise $a$. This strategic effect disappears under vertical separation. In addition, under vertical separation, the separated facility firm has the opposite incentive. In the free-entry market, a reduction in $a$ stimulates new entries and increases the aggregate quantity supplied. Thus, the separated facility firm has a weaker incentive to raise $a$.

\footnotetext{
${ }^{13}$ As is noted in the second paragraph of this section, $a^{S}=a^{I}$ if $c \geq \sqrt{F}$.
} 


\section{Concluding remarks}

Firms often influence the access charge by lobbying and/or manipulating the accounting costs in practice, whereas the rule for calculating the access charge is determined by a neutral government, and there is no room for manipulation in principle. In this paper, we consider a situation wherein the access charge is influenced by the firms through lobbying activities. Under the situation, we mainly discuss the manner in which vertical separation affects the access charge. We find that it is ambiguous as to whether or not vertical separation decreases the lobbying activities and consequently lowers the access charge. When the number of new entrants is large (small) and the incumbent is as efficient as the new entrants, vertical separation decreases (increases) the access charge. We also find that vertical separation can be harmful for welfare. In free-entry markets, however, the result of the equilibrium access charge is clearer. Vertical separation always decreases lobbying activities and consequently lowers the equilibrium access charge.

In this paper, we assume that the lobbying function is given exogenously and investigate whether or not vertical separation reduces the incentive to lobby. Endogenizing the relationship between lobbying activity and the resulting access charge under vertical integration and vertical separation and/or introducing lobbying by multiple players remains an interesting topic for future research. 


\section{References}

Armstrong, M., Sappington, D.E.M., 2006. Regulation, competition, and liberalization. Journal of Economic Literature 44(2), 325-366.

Armstrong, M., Vickers, J., 1998. The access pricing problem with deregulation: a note. Journal of Industrial Economics 46(1), 115-121.

Beard, T. R., Kaserman, D. L., Mayo, J. W., 2001. Regulation, vertical integration and sabotage. Journal of Industrial Economics 49(3), 319-333.

Buehler, S., Gärtner, D., Halbheer, D., 2006. Deregulating network industries: dealing with price-quality tradeoffs. Journal of Regulatory Economics 30(1), 99-115.

Bustos, A.E., Galetovic, A., 2009. Vertical integration and sabotage with a regulated bottleneck monopoly. B.E. Journal of Economic Analysis 8 Policy 9(1), (Topics), Article 35.

Clark, D. J., Foros, Ø., Sand, J. Y., 2010. Foreclosure in contests. Public Choice, forthcoming, http://dx.doi.org/10.1007/s11127-010-9653-2

Dasgupta, P., Stiglitz, J., 1980. Uncertainty, industrial structure, and the speed of R\&D. Bell Journal of Economics 11(1), 1-28.

Davidson, C., Mukherjee, A., 2007. Horizontal mergers with free entry. International Journal of Industrial Organization 25(1), 157-172.

Economides, N., 1998. The incentive for non-price discrimination by an input monopolist. International Journal of Industrial Organization 16(3), 271-284.

Economides, N., White, L. J., 1995. Access and interconnection pricing: How efficient is the 'efficient component pricing rule'? Antitrust Bulletin 40(3), 557-579.

Etro, F., 2007. Competition, Innovation, and Antitrust: A Theory of Market Leaders and Its Policy Implications. Springer: New York.

Gautier, A., Mitra, M., 2008. Regulation of an open access essential facility. Economica $75,662-682$.

Hausman, J. A., 1997. Valuing the effect of regulation on new services in telecommunications. Brooking Papers on Economic Activity, Microeconomics, 1-38.

Higgins, R. S., Mukherjee, A., 2010. Deregulation redux: does mandating access to bottleneck facilities necessarily improve welfare? Public Choice 142(3-4), 363-377.

Hori, K., Mizuno, K., 2006. Access pricing and investment with stochastically growing demand. International Journal of Industrial Organization 24(4), 795-808.

Ida, T., 2001. Network Economics (Nihonhyoronsha, Tokyo, in Japanese).

Ida, T., Anbashi, M., 2008. Analysis of vertical separation of regulators under adverse selection. Journal of Economics 93(1), 1-29. 
Ino, H., Matsumura, T., 2010. What role should public enterprises play in free-entry markets?, Journal of Economics 101(3), 213-230.

Ishida J., Matsumura T., Matsushima, N., 2010. Market competition, R\&D and firm profits in asymmetric oligopoly. Journal of Industrial Economics, forthcoming.

Laffont, J. J., Tirole, J., 1994. Access pricing and competition. European Economic Review 38(9), 1673-1710.

Lahiri, S., Ono, Y., 1988. Helping minor firms reduces welfare. Economic Journal 98, 1199-1202.

Lahiri, S., Ono, Y., 1995. The role of free entry in an oligopolistic Heckscher-Ohlin model. International Economic Review 36(3), 609-624.

Lahiri, S., Ono, Y., 1998. Foreign direct investment, local content requirement, and profit taxation. Economic Journal 108, 444-457.

Lahiri, S., Ono, Y., 1999. R\&D subsidies under asymmetric duopoly: a note. Japanese Economic Review 50(1), 104-111.

Long, N. V., Soubeyran, A., 1996. Lobbying for protection by heterogeneous firms, European Journal of Political Economy 12(1), 19-32.

Loury, G.C., 1979. Market structure and innovation, Quarterly Journal of Economics 93(3), 395-410.

Mandy, D. M., Sappington, D. E. M., 2007. Incentives for sabotage in vertically related industries. Journal of Regulatory Economics 31(3), 235-260.

Marjit, S., Mukherjee, A., 2008. International outsourcing and R\&D: Long-Run implications for consumers. Review of International Economics 16(5), 1010-1022.

Matsumura, T., 2003. Consumer-benefiting exclusive territories. Canadian Journal of Economics 36(4), 1007-1025.

Matsushima, N., 2001. Horizontal mergers and merger waves in a location model. Australian Economic Papers 40(3), 263-286.

Matsushima, N., Matsumura, T., 2003. Mixed oligopoly and spatial agglomeration. Canadian Journal of Economics 36(1), 62-87

Mizuno, K., Shinkai, T., 2006. Delegating infrastructure projects with open access. Journal of Economics 88(3), 243-261.

Ono, Y., 1990. Foreign penetration and national welfare under oligopoly. Japan and the World Economy 2(2), 141-154.

Pecorino, P., 1998. Is there a free-rider problem in lobbying? endogenous tariffs, trigger strategies, and the number of firms. American Economic Review 88(3), 652-60. 
Rey, P., Tirole, J., 2007. A primer on foreclosure. Eds. M. Armstrong, M., Porter, R. eds. Handbook of Industrial Organization, Vol. 3, 2145-2220, North-Holland.

Salant, S. W., Shaffer, G., 1999. Unequal treatment of identical agents in Cournot equilibrium. American Economic Review 89(3), 585-604.

Sappington, D.E.M., 2006. On the design of input prices: Can TELRIC prices ever be optimal? Information Economics and Policy 18(2), 197-215.

Tullock, G., 1980. Efficient Rent-Seeking, in Toward a Theory of the Rent-Seeking Society, Buchanan, J.M., Tollison, R.D., Tullock, G., Eds., Texas A\&M Press.

Ushio, Y., 2000. Welfare effects of commodity taxation in Cournot oligopoly. Japanese Economic Review 51(2), 268-273.

Viscusi, W. K., Harrington, J. E., Vernon. J. M., 2005. Economics of Regulation and Antitrust. 4th Edition, MIT Press.

Vogelsang, I., 2003. Price regulation of access to telecommunications networks. Journal of Economic Literature 41(3), 830-862

Yamazaki, T., 2004. Tariff rate as a public good. Review of International Economics 12(1), 95-107. 


\section{Appendix}

Proof of Proposition 1 First, we show (ii). Given $a$, the difference between $\partial \pi_{0}^{S S} / \partial a$ in (3) and $\partial \pi_{1}^{I S} / \partial a$ in (2) is given as

$$
D \equiv-\frac{(n-3)(v-n c-2 a)}{(n+1)^{2}} .
$$

If $n=3, D=0$ regardless of the parameters. This implies $a^{S}=a^{I}$.

Next, we show (i) and (iii). We show the following three properties:

(a) $\partial \bar{\pi}_{1}^{I S} / \partial a=\partial \bar{\pi}_{0}^{S S} / \partial a=(n-1) c$ when $a=(v-n c) / 2$;

(b) $\partial^{2} \bar{\pi}_{1}^{I S} / \partial a^{2}<0$ and $\partial^{2} \bar{\pi}_{0}^{S S} / \partial a^{2}<0$;

(c) $\partial^{2} \bar{\pi}_{1}^{I S} / \partial a^{2}<\partial^{2} \bar{\pi}_{0}^{S S} / \partial a^{2}$ holds if $n<3$, $\partial^{2} \bar{\pi}_{1}^{I S} / \partial a^{2}>\partial^{2} \bar{\pi}_{0}^{S S} / \partial a^{2}$ holds if $n>3$.

If the three properties hold, from Figure 1, it is clear that Proposition 1(i) and Proposition 1(iii) hold.

We first show that (a) holds. $\partial \bar{\pi}_{1}^{I S} / \partial a$ and $\partial \bar{\pi}_{0}^{S S} / \partial a$ are given as

$$
\begin{aligned}
\frac{\partial \bar{\pi}_{1}^{I S}}{\partial a} & =\frac{2(n-1)(v-n c+(n-1) a)}{(n+1)^{2}}+\frac{(n-1)(v+c-4 a)}{n+1} \\
\frac{\partial \bar{\pi}_{0}^{S S}}{\partial a} & =\frac{n v-c-2 n a}{n+1} .
\end{aligned}
$$

Substituting $a=(v-n c) / 2$ into these two equations yields $\partial \bar{\pi}_{1}^{I S} / \partial a=\partial \bar{\pi}_{0}^{S S} / \partial a=(n-1) c$. This implies (a).

Second, we show that (b) holds. Differentiating $\partial \bar{\pi}_{1}^{I S} / \partial a$ and $\partial \bar{\pi}_{0}^{S S} / \partial a$ with respect to $a$, we have

$$
\frac{\partial^{2} \bar{\pi}_{1}^{I S}}{\partial a^{2}}=-\frac{2(n-1)(n+3)}{(n+1)^{2}}<0, \quad \frac{\partial^{2} \bar{\pi}_{0}^{S S}}{\partial a^{2}}=-\frac{2 n}{n+1}<0 .
$$

Thus, (b) holds.

Finally, we show that (c) holds. The difference between $\partial^{2} \bar{\pi}_{1}^{I S} / \partial a^{2}$ and $\partial^{2} \bar{\pi}_{0}^{S S} / \partial a^{2}$ is given as

$$
\frac{\partial^{2} \bar{\pi}_{1}^{I S}}{\partial a^{2}}-\frac{\partial \bar{\pi}_{0}^{S S}}{\partial a}=\frac{2(3-n)}{(n+1)^{2}} .
$$

Thus, (c) holds. 


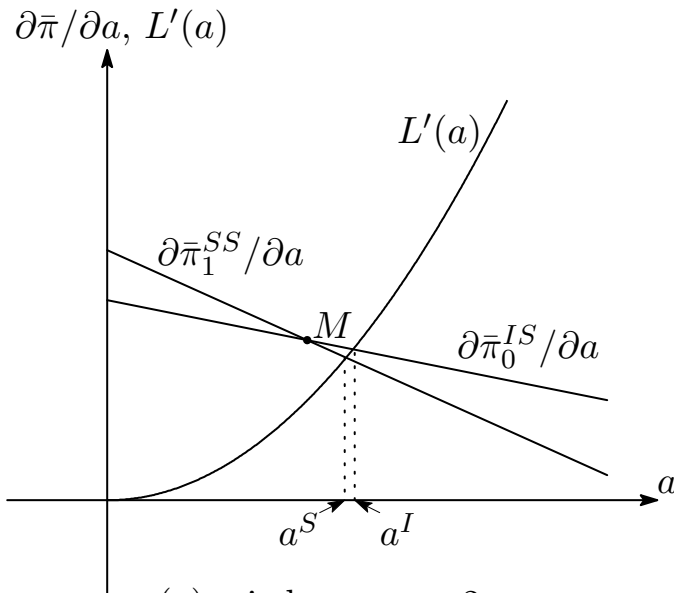

(a) $c$ is large, $n=2$

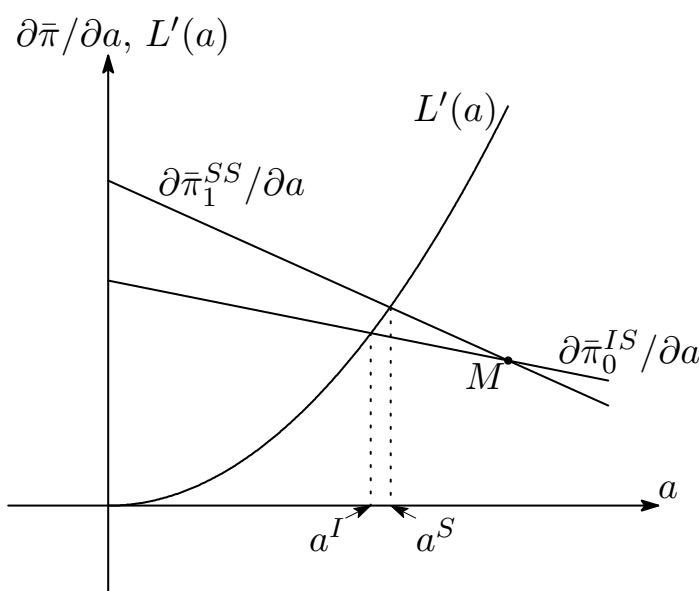

(c) $c$ is small, $n=2$

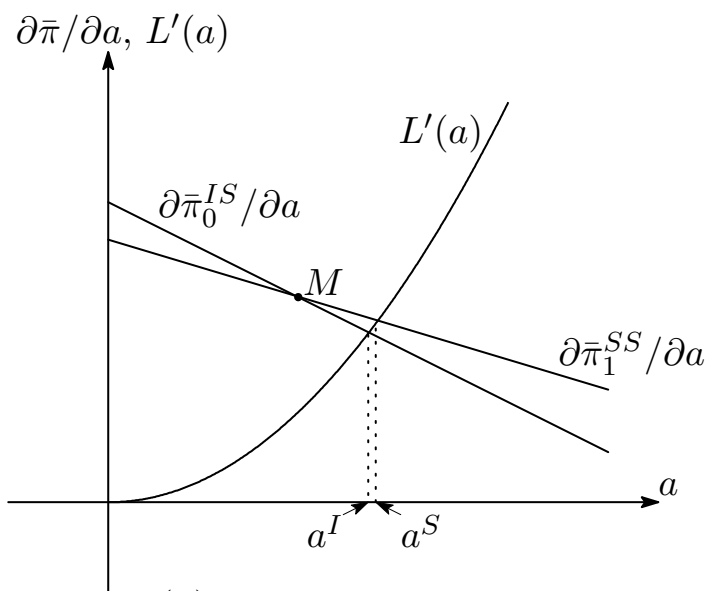

(b) $c$ is large, $n>3$

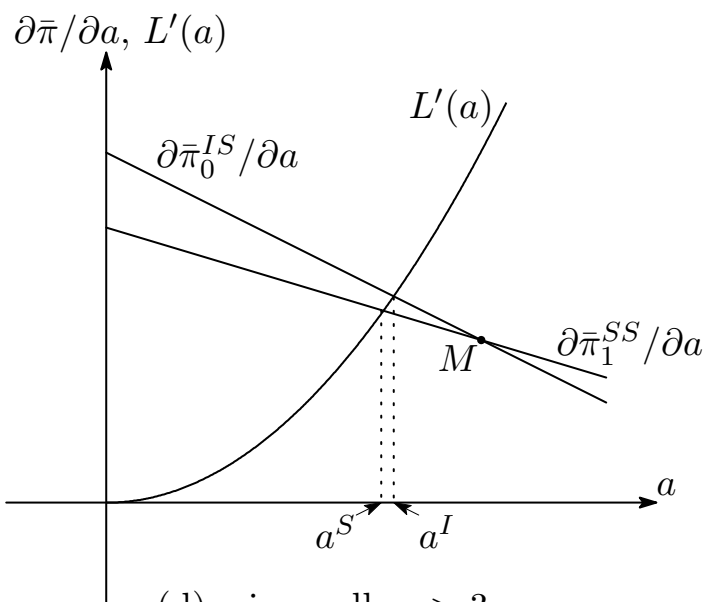

(d) $c$ is small, $n>3$

Figure 1: The marginal gain and cost of raising $a$.

Horizontal axis: The access charge level, $a$,

Vertical axis: The marginal gain and cost of raising $a, \partial \pi_{0}^{I S} / \partial a$ and $\partial \pi_{1}^{S S} / \partial a, L^{\prime}(a)$, $M$ : The intersection of the two curves, $(a, \partial \bar{\pi} / \partial a)=((v-n c) / 2,(n-1) c)$. 


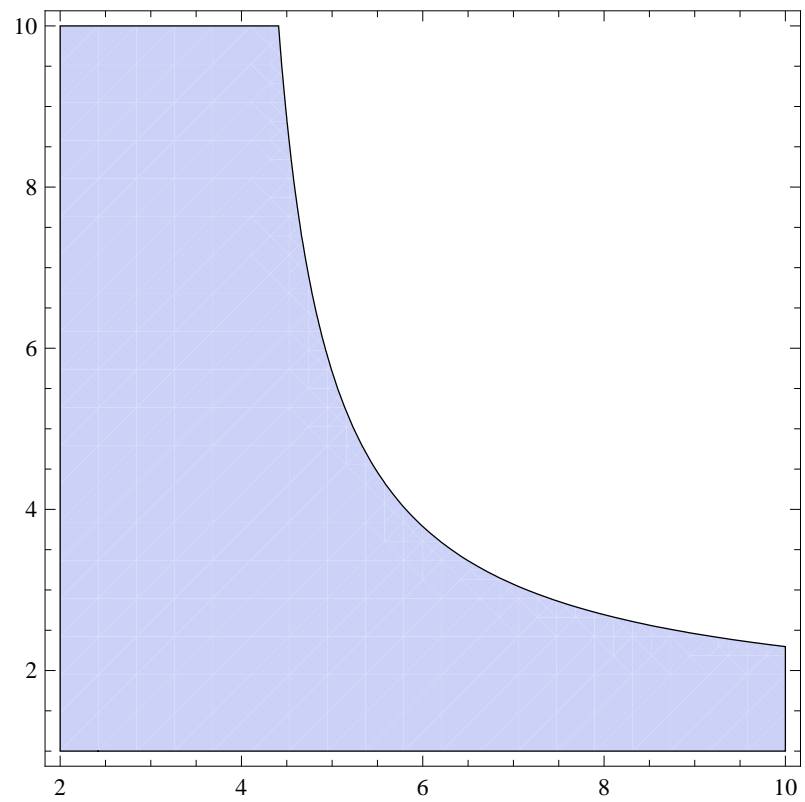

Figure 2: The condition wherein vertical separation reduces welfare Horizontal axis: The number of firms $(n)$,

Vertical axis: The parameter of the investment function $(\phi)$, Shaded area is that the condition holds. 